Article

\title{
The Inclusion of Students With Disabilities: Challenges for Italian Teachers During the Covid-19 Pandemic
}

\author{
Maddalena Colombo * and Mariagrazia Santagati \\ Department of Sociology, Università Cattolica del Sacro Cuore, Italy \\ * Corresponding author (maddalena.colombo@unicatt.it)
}

Submitted: 30 October 2021 | Accepted: 5 January 2022 | Published: 19 May 2022

\begin{abstract}
In March 2020 all schools in Italy were closed due to the Covid-19 pandemic, and the novelty of distance learning was introduced. During the 2020-2021 school year, pre-primary and primary schooling was carried out in situ, while secondary education was re-organized into a mixed system, with students spending $50 \%$ of their time attending classes from home, in distance learning. This reconfiguration was a challenge to students, teachers, and parents, affecting the learning experience of the most vulnerable students and students with disabilities, particularly. It necessarily brought into question Italy's "progressive" legal framework for "school inclusion." The scope of the present article is to analyze the teaching activities carried out with students with disabilities in Italy during the first wave of the emergency lockdown and their consequent challenges for school inclusiveness. An overview of the Italian inclusive model in education and the national measures adopted to guarantee the right to education during times of school closure/restriction is outlined. We have sought to test the hypothesis that distance learning may introduce many risks for inclusion (resulting in a "downgrading inclusion," that is, a decline of the level of inclusion already reached for students with disabilities), but it may also present an improvement in how teachers address these students and their needs. To this end, after reporting data from the available studies on this target, we provide insights from a web questionnaire submitted to a non-probabilistic sample of nearly 150 primary and (lower and upper) secondary school teachers. Results showcase that, though with a general worsening of school inclusion, in some cases, teachers were actually able to support students with disabilities and their families in a new, customized, empathetic, and more attentive manner.
\end{abstract}

\section{Keywords}

Covid-19; distance learning; Italy; school inclusion; school lockdown; school-family relationship; students with disabilities; support teachers; vulnerable students

\section{Issue}

This article is part of the issue "Educational Inclusion of Vulnerable Children and Young People after Covid-19" edited by Spyros Themelis (University of East Anglia) and Angela Tuck (Pakefield High School).

(C) 2022 by the author(s); licensee Cogitatio (Lisbon, Portugal). This article is licensed under a Creative Commons Attribution 4.0 International License (CC BY).

\section{Introduction}

In March 2020 all schools in Italy were closed due to the Covid-19 pandemic, and the novelty of distance learning was introduced. During the 2020-2021 school year, pre-primary and primary schooling took place regularly, while secondary education was re-organized into a mixed system, with students spending $50 \%$ of their time attending classes from home, in distance learning. This reconfiguration posed a challenge to every stu- dent, teacher, parent, and school manager, highlighting latent educational problems and unveiling educational inequalities already affecting the most vulnerable students. Among this group, students with disabilities more generally, and the issue of their inclusion in education specifically, have been an educational priority during the Covid health crisis.

After presenting an overview of the Italian inclusive model of education and a review of the literature investigating the impact of lockdown on children with 
disabilities, this article will try to test the hypothesis that distance learning offers students with disabilities a combination of both risk and improvement factors. Empirical evidence generated from a web questionnaire submitted to a non-probabilistic sample of nearly 150 Italian primary and secondary school teachers will be discussed.

\section{The Italian Inclusive Model of Education}

The Italian education system, as outlined by the 1946 Italian Constitution, is characterized by its inclusiveness: The document fosters a non-discriminatory system where access to education is ensured regardless of gender, race, social status, ability, and difference of opinion, and article 34, comma 1, stresses that "schools are open to everyone." During the second half of the 20th century, a wide cultural movement for the rights of people with disabilities took place and improved aspects of inclusivity in Italian society and its institutions.

Since the mid-1970s, students with disabilities have been the object of specific legislation in Italy (Law n. 517/1977) inspired by the principle of school integration (Dempsey, 2001), which has made it mandatory to recruit a support teacher certified by the National Health System for every four students with a disability in each class. The law, which has not been changed, features one of the most "progressive" legal frameworks in Europe (European Agency for Development in Special Needs Education, 2003), in terms not only of de-segregation but also of integration in mainstream education. So far, other norms have been promulgated, aimed at broadening the range of needs classified as "special" and eligible for compensations and dispensations during a given educational career: Of these, Law no. 104/1992 and Law no. $170 / 2010$ have been the most significant. An organic set of rights was established in compulsory education (which has been extended from eight to 12 years, or until the age of 18 in 2007) and the creation of an Individual Educational Plan (PEI) has become mandatory for students with disabilities at all school levels. A meaningful measure adopted to further promote educational inclusion was the Directive of the Ministry of Education, passed 27 December 2012, which distinguishes SEN students into three sub-groups: those with one or more disabilities, those with learning difficulties (ADHD, dyslexia, etc.), and those with a socio-economic and/or linguistic disadvantage due to ethnic background, economic deprivation, and/or family poverty. This distinction aims to develop more customized interventions. In this article we chose to focus on the first subgroup of special needs students, those with disabilities (be these physical, psychological, or sensory) given that they are the only ones who are assigned a support teacher. Accordingly, we use the term "support teacher" and not "special educational needs teacher," as the latter is not recognized as such in Italy.

As a positive impact of this legislation, there has been an increase in the target population, which now includes 270,000 students with disabilities $13.5 \%$ of the whole school population; see Istat, 2020). They can benefit from a student-to-teacher ratio of 1:3 thanks to a provision of about 203,000 support teachers, mainly operating in public schools, who represent $29.8 \%$ of all teachers employed (MIUR, 2021). Each student with a disability has the right to have a support teacher for 14.1 hours per week on average (as per the 2018-2019 school year) in addition to the classroom teacher, but this amount is still perceived as insufficient, given that $6 \%$ of parents have appealed against this allocation. Moreover, the turnover among support teachers is particularly high, given that $57 \%$ change yearly, and this is another reason parents complain (Istat, 2020).

Overall, Italian school integration policy can be considered as inclusive (D'Alessio, 2011), since it is based on a neat anti-discriminatory and de-segregating legislation, and focused on equity, access, opportunity, and rights. At a formal level, this approach is consistent with the "social model" of disability which has inspired the ICF framework (Barnes, 2012), because the help provided to students is not limited to the school environment but is located at the crossroads of school and health/social services, both of whom are responsible for the certification of disability and for the definition of support measures that will follow. These measures, however, are often not applied in full due to the different standards of diagnosis applied in the different regional healthcare systems and the local disparity in the availability of support teachers. Therefore, the measures do not achieve their full potential and, in some cases, this can hamper the path to inclusion. Moreover, the sociocultural climate, especially in secondary education, is often not yet ready to accept and adopt them fully, something we shall return to later in the article.

\section{The Inclusion of Students With Disabilities in Italy During Covid-19}

\subsection{School Closure and Social Distancing}

Italy was the first Western country to close all educational institutions nationwide at the beginning of March 2020. To this day, the country has navigated through different phases: from the first general lockdown (March-June 2020) to the re-opening of schools (September through mid-October 2021) with protection measures and social distancing in the classroom, to a long period characterized by the alternation of students in secondary schools (divided into two groups who could be present online or at school, alternatively) until the end of the 2020-2021 school year (Pavolini et al., 2021).

No doubt, the urgent and drastic measure of suspending all early childhood education services and schools (Decree-Law n. 6 of 23 February 2020) marked an unprecedented scenario for Italy. One month into the pandemic the Minister of Education issued the first operational indications for distance learning activities (DAD): 
to maintain class relationships and learning environments and to contrast isolation and demotivation among students. Many Italian schools started distance learning almost immediately while awaiting more specific national guidelines. They carried out a set of different educational activities using ICT, videoconferencing, and assigning homework and study materials through digital platforms (or via e-mail and WhatsApp if the connectivity was too weak for synchronic exchanges). Social activities with students online were the most widespread practice (Indire, 2020). The Ministerial Note no. 388 of 17 March 2020 suggested paying special attention to students with disabilities: Support and curricular teachers were invited to maintain the interaction with these students and their parents, albeit remotely, to continue supporting them through distance learning and to monitor the effective implementation of their PEI. Meanwhile, the website of the Ministry of Education was expanded to include a section called "online inclusion," aimed at supporting school staff by providing tools, experiences, and webinars they could use with students with disabilities (Pellegrini \& Maltinti, 2020).

During the summer of 2020, in preparation for the re-opening of schools in September, the Ministry of Education delivered the guidelines for integrated digital teaching (DDI), which stipulated that each school was required to prepare a specific plan, capitalizing on the experience gained during the months of lockdown. Each school was also asked to survey any specific needs for tablets, PCs, ICT connections, and other infrastructural equipment for students and teachers, and make sure those needs were catered to. Whereas during the first lockdown students with disabilities were subjected to the same restrictions imposed on all students (which placed a heavy burden on their families), from September 2020 onwards they received special provisions: In the case of blended learning (remote and presential), they would be given priority in receiving face-to-face learning with their teachers to avoid both physical isolation and care deprivation-both of which are at risk in the case of prolonged exclusion from presential learning among students with disabilities.

Ministerial Decree no. 39, issued 26 June 2020, identifies disability and school inclusion as educational priorities for the 2020-2021 school year. By adopting ordinary and extraordinary measures, schools have been required to ensure that students with SENs, especially those with disabilities, be present at school, by creating customized face-to-face activities based on the number of students, type(s) of disability, and available professional resources; in some cases, they were even dispensed from using an (otherwise mandatory) protective face mask.

Given the sharpening of the pandemic, the 2020-2021 school year started with many concerns: Several interruptions to regular school attendance (based on differential criteria of risk of contagion for each region) and different forms of distance learning were carried out, especially in upper secondary educa- tion. With the Prime Minister Decree of 2 March 2021, one year after the start of the Covid-19 emergency, all schools were closed again, allowing only teachers (who, in the meantime, had been among the first categories of workers to take part in the vaccination campaign) and students with special needs to enter school grounds.

\subsection{Studies on the Impact of Lockdown on Children With Disability}

Since 2020, studies began to investigate the indirect effects of prolonged school closures on students, both in terms of learning and of their physical and mental health (Schleicher, 2020). The learning loss (Agostinelli et al., 2020) appeared difficult to regain, especially for pupils from disadvantaged and minority backgrounds, with an increased likelihood that school inequalities would worsen (Kuhfeld et al., 2020). One year later, in March 2021, with almost half of the world's students still affected by partial or full school closures (UNESCO, 2021), the global effects of lockdown on students began to become clearer. Due to the lack of ICT devices, poor connectivity, and the absence of direct teacher-student interaction, distance learning proved its inadequacy as a means of ensuring universal access to education. Indeed, it has been estimated that one-third of school-age children in the world have been excluded from distance learning activities (UNICEF, 2021).

Little research has specifically focused on students with disabilities. International analyses remark on the negative consequences of home confinement and "home-based distance learning," and point out that distance learning programs reduce school participation (Petretto et al., 2020; United Nations, 2020). Italian studies also highlight the presence of additional problems for this group during the pandemic. Between April and June 2020 , over $23 \%$ of students with disabilities (about 70,000) did not take part in distance learning activities (Istat, 2020). The reasons are mainly linked to the severity of their disability/ies, the difficulty in ensuring the collaboration of family members, and the family's socioeconomic disadvantage. In particular, the few studies carried out during the pandemic focused on the role played by three factors: (a) availability of ICT devices at home and school (Filosa \& Parente, 2020; Indire, 2020); (b) level of family collaboration; and (c) readjustment of the objectives of the PEI.

A month after the first school closure, an explorative survey based on nearly 3,000 teachers (lanes \& Bellacicco, 2020), showed that more than one student with a disability out of three was excluded from distance teaching, while for $20 \%$ only individualized activities were contemplated. Exclusion seemed to be widespread across different school levels: In more than $20 \%$ of cases, no digital materials were made available for these students; their adaptation, when it occurred, was assigned only by support teachers. Sometimes the relationship with families and between teachers appeared to be 
positive, whereas peer involvement was found to be lacking, leading to isolation for students with disabilities (Fondazione Agnelli, 2020).

In a local study carried out in a Northern Italian region (Parmigiani et al., 2020), 24\% of the nearly 800 teachers surveyed declared that the families of students with disabilities did not have ICT devices at their disposal that were sufficiently powerful to launch videoconferencing software or to download the applications necessary to utilize digital materials. Most families (65\%) collaborated in many ways with teachers by coaching their children, giving continuous feedback, supporting them emotionally, and helping teachers during the personalization process. Most teachers declared having had a good level of team collaboration (70\%), whilst 154 teachers noted situations where support teachers were excluded from the teaching team and left alone to manage their assigned students with disabilities. Obstacles to successful online inclusive activities were lack of physical contact, lack of face-to-face interaction, lack of attention, and lack of participation. Among others, the lack of social moments appears to be the most important problem, since there are difficulties in maintaining contact with the rest of the class. Finally, national studies emphasize that in one school out of 10 no support teacher took part in specific courses for the appropriate use of ICT in education: Therefore, a scarce preparation in the management of distance teaching is hypothesized for this group of teachers, with possible negative consequences on students with disabilities, the impact of which has not yet been fully estimated (Censis, 2020).

\section{Hypothesis and Method}

There is no doubt that the inclusive approach of the Italian education system has suffered during the pandemic, and the consequences may have had an impact over and beyond the students themselves, on teachers and parents. No teacher, however well prepared, can be inclusive, in conditions of permanent external danger and with minimal (or no) institutional support. Teachers were able to cope with the emergency mostly at an individual level by drawing upon their personal experience with ICT, goodwill, and capability to test out new teaching solutions through trial-and-error and by learning how to grab and exploit public digital resources (online, radio and TV materials, online tutorials, etc.) available at the given moment.

Given the limited studies on this issue, our first exploratory hypothesis is that, during this emergency, which created new working conditions for both regular and support teachers, the inclusion of students with disabilities in the educational environment could face a risk of decline ( $\mathrm{H} 1)$. On the other hand, through specific digital resources, teaching tools, and various communication channels, we believe that teachers may have also found ways to implement practices that made students with disabilities more directly involved and motivated in learning $(\mathrm{H} 2)$.
To test these hypotheses, we use data from an online survey carried out in December 2020. Using a Google questionnaire circulating on Facebook, we reached a non-probabilistic sample of Italian teachers/educators employed in different school divisions. The sample includes 147 respondents (95\% female), distributed as follows: $53 \%$ from primary schools, $20 \%$ from lower secondary schools, and $27 \%$ from upper secondary schools, with an acceptable territorial distribution (about 50\% from the North, 15\% from the Center, and 35\% from the South of Italy). The sample included classroom teachers $(52 \%)$, support teachers (34\%), and other professionals (14\%) responsible for students with disabilities, such as educators, personal assistants, and tutors. The questionnaire (made up of 20 closed and open questions) aimed at collecting experiences and opinions about the teaching strategies adopted during the first lockdown (March-June 2020) with students with disabilities, their emotions and feelings surrounding their work at this time, and the relationship maintained with these students' parents.

No doubt, the self-selection of the sample represents the main methodological limitation of this investigation, whose results are not useful for statistical inferences and generalization, given that the sample presumably includes only the most engaged and motivated teachers. However, the data, which derives from voluntary participation in the survey, may produce an early picture, in real-time, of teachers' experience with students with disabilities during the first phase of the pandemic and their teaching activities. The distribution of the sample in terms of teachers' role, gender, and territorial distribution mirrors the general situation of teaching in Italy, with only an underrepresentation of teachers working in the central regions of Italy.

\section{Data Analysis and Results}

The data analysis is articulated in two steps: First, we offer a general frame of the activities of distance education and of the difficulties encountered by teachers addressing the needs of students with disabilities during the first school lockdown in Italy (Section 5.1). Considering the sample's limitations, as described above, the data analysis has been limited to a frequency distribution. Some closed questions showcased a list of frequency options that respondents were invited to fill out to indicate if they chose certain activities and tools or faced difficulties with families and students with disabilities (possible responses were: never, sometimes, often, or always; no missing responses were allowed).

Second, we carried out a more in-depth analysis of the following two open questions in the questionnaire (Section 5.2):

1. What negative and positive aspects emerged from the relationship with parents of students with disabilities? 
2. What negative and positive elements emerged from the relationship with students with disabilities?

A thematic analysis of the written answers given by respondents allows us to outline teachers' opinions about their work with students with disabilities and their parents during the pandemic and summarize the emerging trends in a final analytical matrix (see Table 3). Ambivalent aspects, emerging from the teacher-student and teacher-parent relationship, are interpreted identifying core dimensions and categories to reach a deeper understanding of the educational dynamics concerning students with disabilities in times of emergency.

\subsection{Learning Activities, Students Difficulties, and School-Family Communication}

The Covid-19 emergency lockdown has been lived by many teachers with a sense of inadequacy (65\%), stress (62\%), anxiety (45\%), and frustration (37\%). Despite many respondents $(67 \%)$ reporting they would plan lessons taking into consideration the different learning needs of their students, the majority (53\%) also claim that working alone (that is, without their teaching team) was the first impediment due to the conditions of lockdown.

If we take a closer look at the activities, they were able to carry out via distance learning, the "live lesson" was the most adopted across all grades, especially the common lesson with the entire class (57-70\% opted for this "often/daily"). Individual lessons by support teachers were offered "often/daily" by $37-57 \%$ of respondents (more in primary and upper secondary education than in lower secondary schooling), but there are $22.5 \%$ of lower secondary teachers who did not offer individual lessons to students with disabilities at all. The most popular teaching tool among respondents was the use of PowerPoint presentations. In primary schools, recorded lessons were also used frequently (42.5\% "often/daily") with students with disabilities, more than in other grades (33.5\% "often/daily" in lower secondary classes, 21\% in upper secondary classes). Online exercises were typically assigned more by primary school teachers $(50.5 \%$ "often/daily"), especially if compared with upper secondary teachers (32.5\% "often/daily").

On the whole, teachers included in this sample were quite active in addressing students with disabilities, albeit without didactic innovation and/or customization of activities. They tried to avoid isolation and disconnection among these students by choosing a topdown model rather than more discursive and dialectic modes. One negative point that emerges from the questionnaire is that $27 \%$ of primary school, $26 \%$ of lower secondary school, and $22.5 \%$ of upper secondary teachers did not do anything (or almost anything) specifically for students with disabilities (i.e., they marked "always/often" or "sometimes" for the item no activity for pupils with disabilities).
To test the sensitivity of respondents to the learning needs of students with disabilities, we asked them to report the main difficulties mentioned by students during school closures (Table 1). Students mostly felt an impediment in interaction with both classmates (42-47\% "often/daily" in secondary education) and teachers (32\% "often/daily" in primary education, $43 \%$ in lower secondary education). After that, the main impediment was the weakness of their Internet connection (38\% "often/daily" in primary education, $25 \%$ in lower secondary education, and $34 \%$ in upper secondary education)-only a few students did not have any connection problems ( $5 \%$ in high schools, $10 \%$ in primary schools, and none in middle schools).

According to teachers, the younger students with disabilities are the harder they find it to cope with digital tools. In primary schools, difficulties in using ICT devices or digital platforms are greater than in secondary schools, and often younger children must share devices with other family members more than their teenage counterparts. The same appears to be true concerning home space: Difficulties in studying at home for the lack of a dedicated room to study is more frequent among disabled children (according to teachers, 20.5\% find this aspect difficult "often/daily") than adolescents (only 10,5\%). This could be, at least in part, the reason why there is a meaningful share of students with disabilities who have difficulty in following online teaching activities: According to the respondents, $30.5 \%$ of primary school children "often/daily" cannot follow sync lessons and video calls regularly (versus $18 \%$ in lower and upper secondary schools).

To sum up, teachers see age as intersecting with the presence of a disability as a determinant of the different responses of students to the proposed learning activities: While children lacked more structural and digital tools and support, teenagers and adolescents were more challenged by the difficulty in understanding and doing specific school assignments, also because the personal interaction with teachers was strongly limited by distance learning.

Many teachers and support teachers acknowledge the importance of the parents' mediation to improve the quality of students' response and learning outcomes. The questionnaire enquired about the different solutions and tools adopted by teachers to guarantee a stable relationship (and communication channel) with the parents of students with disabilities (Table 2). Parents who were not contacted/reached at all during the school lockdown are $15 \%$ in primary schools, $8 \%$ in middle schools, and $16.5 \%$ in high schools. In secondary education, a considerable share of respondents did not have any contact with parents through digital platforms: In upper secondary schools, $24 \%$ reported "never" having any contact, the same answer as $17.5 \%$ of respondents from lower secondary schools. An even higher number of teachers did not contact parents either via WhatsApp or through individual text messages (39-40\% of the former 
Table 1. Main difficulties mentioned by students during school closures.

\begin{tabular}{|c|c|c|c|c|c|c|c|c|c|}
\hline \multirow[t]{2}{*}{ Difficulty in: } & \multicolumn{3}{|c|}{ Primary school } & \multicolumn{3}{|c|}{ Lower Secondary school } & \multicolumn{3}{|c|}{ Upper secondary school } \\
\hline & Never & Sometimes & $\begin{array}{l}\text { Often/ } \\
\text { daily }\end{array}$ & Never & Sometimes & $\begin{array}{l}\text { Often/ } \\
\text { daily }\end{array}$ & Never & Sometimes & $\begin{array}{c}\text { Often/ } \\
\text { daily }\end{array}$ \\
\hline Peer interaction & 13.5 & 68.0 & 18.5 & 21.5 & 36.0 & 42.5 & 7.5 & 45.0 & 47.5 \\
\hline $\begin{array}{l}\text { Student-teacher } \\
\text { interaction } \\
\text { (mediated also } \\
\text { by screens) }\end{array}$ & 14.0 & 54.5 & 31.5 & 21.5 & 35.5 & 43.0 & 10.5 & 65.5 & 24.0 \\
\hline $\begin{array}{l}\text { Sharing devices } \\
\text { with other family } \\
\text { members }\end{array}$ & 16.5 & 46.0 & 37.5 & 10.5 & 64.5 & 25.0 & 34.0 & 53.0 & 13.0 \\
\hline Internet connection & 10.5 & 51.5 & 38.0 & - & 75.0 & 25.0 & 5.5 & 60.5 & 34.0 \\
\hline Doing homework & 17.5 & 63.5 & 19.0 & 3.0 & 77.5 & 19.5 & 21.5 & 51.5 & 27.5 \\
\hline $\begin{array}{l}\text { Using ICT device } \\
\text { and platform }\end{array}$ & 14.5 & 62.0 & 23.5 & 12.5 & 68.0 & 19.5 & 14.0 & 74.0 & 12.0 \\
\hline $\begin{array}{l}\text { Following live/sync } \\
\text { lessons }\end{array}$ & 14.0 & 55.5 & 30.5 & 14.0 & 68.0 & 18.0 & 18.5 & 63.0 & 18.5 \\
\hline $\begin{array}{l}\text { Doing oral } \\
\text { interrogations }\end{array}$ & 32.5 & 55.0 & 12.5 & 17.5 & 72.0 & 10.5 & 18.5 & 63.0 & 18.5 \\
\hline Studying at home & 26.5 & 53.0 & 20.5 & 28.5 & 57.5 & 14.0 & 31.5 & 58.0 & 10.5 \\
\hline $\begin{array}{l}\text { Following async } \\
\text { lessons }\end{array}$ & 23.0 & 64.5 & 12.5 & 21.5 & 71.0 & 7.5 & 29.0 & 52.0 & 19.0 \\
\hline
\end{tabular}

Notes: These are answers to the closed question: How often during lockdown did students with disabilities refer to the following difficulties? Percentage on the row total per each school division; 78 respondents are teachers/educators at primary schools, 29 are teachers/educators at lower secondary schools, 39 are teachers/educators at upper secondary schools (the same applies to Table 2). Source: $\operatorname{UCSC}(2020)$.

Table 2. Tools adopted by teachers to remain in contact with families of students with disabilities.

\begin{tabular}{|c|c|c|c|c|c|c|c|c|c|}
\hline \multirow[t]{2}{*}{ Tool } & \multicolumn{3}{|c|}{ Primary school } & \multicolumn{3}{|c|}{ Lower Secondary school } & \multicolumn{3}{|c|}{ Upper secondary school } \\
\hline & Never & Sometimes & $\begin{array}{l}\text { Often/ } \\
\text { daily }\end{array}$ & Never & Sometimes & $\begin{array}{l}\text { Often/ } \\
\text { daily }\end{array}$ & Never & Sometimes & $\begin{array}{c}\text { Often/ } \\
\text { daily }\end{array}$ \\
\hline Platform & 7.5 & 24.0 & 68.5 & 17.5 & 17.5 & 65.0 & 24.0 & 38.0 & 38.0 \\
\hline $\begin{array}{l}\text { Individual WhatsApp } \\
\text { message }\end{array}$ & 15.0 & 23.0 & 62.0 & 39.0 & 39.0 & 22.0 & 40.5 & 13.5 & 46.0 \\
\hline E-mail to parents & 14.0 & 31.5 & 54.5 & 10.5 & 54.0 & 35.5 & 19.0 & 48.5 & 32.5 \\
\hline $\begin{array}{l}\text { WhatsApp group } \\
\text { with parents }\end{array}$ & 26.5 & 25.0 & 48.5 & 53.5 & 29.5 & 17.0 & 61.0 & 19.5 & 19.5 \\
\hline Digital school register & 19.0 & 28.0 & 53.0 & 22.0 & 22.5 & 55.5 & 21.5 & 24.5 & 54.0 \\
\hline School website & 28.0 & 38.0 & 34.0 & 28.5 & 28.5 & 43.0 & 32.5 & 32.5 & 35.0 \\
\hline $\begin{array}{l}\text { Word-of-mouth } \\
\text { among parents }\end{array}$ & 32.5 & 39.5 & 28.0 & 63.0 & 22.5 & 14.4 & 69.0 & 21.5 & 9.5 \\
\hline $\begin{array}{l}\text { No contact with } \\
\text { parents }\end{array}$ & 67.5 & 17.0 & 15.5 & 68.0 & 24.0 & 8.0 & 64.0 & 19.5 & 16.5 \\
\hline
\end{tabular}

Notes: These are answers to the closed question: How often during lockdown did you use the following tools to remain in contact with families? Percentage on the row total per each school division. Source: UCSC (2020). 
responded "never"), and the majority didn't participate in parent-led class chatrooms (53-61\% of respondents said "never"). The use of institutional top-down channels, i.e., the digital school register and the school website, was frequent and widespread among secondary school teachers (54-55\% said they "often/daily" used the digital register, 43-35\% said they "often/daily" used the school website). A large share of respondents "never" used the word-of-mouth system of communication (63\% in middle schools, $69 \%$ in high schools).

On the contrary, in primary schools, teachers dealt with the need for a stable school-family communication by varying channels more than in secondary schools, moving freely between more formal and informal and horizontal channels of communication. They "often/daily" used emails (54\%), exchanges through the platform (68.5\%), the digital school register (53\%), and word-of-mouth (28\%).

The closed questions of the questionnaire are too narrow to fully understand the process of communication between teachers and parents; they can give us information about teachers' behavior but not details on the feedback from parents. Moreover, they highlight only the frequency with which each tool was used and not its efficacy. Thus, we followed up with the following question: Is the choice of daily communication through "institutional" and top-down channels more successful than informal and peer-based channels to foster the independence of students with disabilities, or does it fail by bypassing or underestimating the importance of the parent-teacher relationship? In next section, we are going to focus on these questions.

\subsection{Teachers' Opinions on Distance Learning: Negative and Positive Consequences on Students with Disabilities and Their Families}

In this section we are going to examine the answers to two open-ended questions included in the questionnaire that allowed us to reconstruct teachers' opinions on their professional experience during the Covid emergency lockdown, considering both negative and positive aspects that emerged in their relationship with students with disabilities, in activities of distance learning, and during communication processes with their families. This part of the questionnaire enabled us to identify not only the challenges and difficulties experienced by teachers working with students with disabilities and their families, but also highlight positive experiences and good relationships, as we have resolved to do in our hypotheses.

The following thematic analysis compares negative and positive aspects emerging from the answers of curricular and support teachers of primary and secondary school to these open-ended questions. First, we consider the impact and consequences of school closure on the relationship between teachers and families with children with disabilities; secondly, we look at the changes and transformations in the relationship between teach- ers and students with disabilities, trying to identify core dimensions and categories that should allow us to comprehend the new educational dynamics of this target of students.

With regards to the teacher-family relationship, the answers to the open questions highlight the insurgence of new stress factors affecting the lives of families with students with disabilities. Teachers report closures, rigidities, and tensions with parents when they assigned students with disabilities different or "separate" activities. They emphasize the difficulty in building positive collaborations between schools and families due to a lack of common strategies, excessive (or rather, an anxious form of) support from parents worried about learning loss and wanting to improve their children's school performance, and a demanding attitude from parents towards teachers. If teacher-parent relations are not based on common and cooperative strategies, the partnership is ineffective with possible role conflicts and mutual distrust. Over-delegation to teachers, with requests for extra-curricular support, or excessive protection and involvement among parents are the two main risks, at opposite ends of the spectrum, but both indicators of a confusion between the adults' roles. The difficulties in cooperating are also due to insufficient ICT devices and problems with internet connection at home, with consequent feelings of discouragement, anxiety, or frustration for not being able, as adults and educators, to support students adequately. Below are a few quotes collected from the questionnaire:

With some parents there was a closure that, unfortunately, affected part of the progress that could have been achieved had there been an effective collaboration. (Class teacher, primary school)

Probably parents help students during remote class assessments. The evaluation is thus distorted, and it is very difficult to identify the real gaps and difficulties on which to intervene. Sometimes it seems that for the family the priority is the diploma and not a real learning experience. (Support teacher, upper secondary school)

The students themselves cannot understand what their strengths and weaknesses are. Why do parents feel the need to help their children with assessments? Do they want to reinforce their self-esteem? Why don't they believe they can do it themselves? I don't know what the reasons are, so I refrain from judging. (Support teacher, upper secondary school)

However, teachers point out that the forced distance also revealed the added value of distance education in terms of improvement of communication and exchanges between teachers and parents. In primary school, informal and direct contacts via WhatsApp with parents increased, in turn boosting and improving confidence, 
mutual listening, and dialogue between families and teachers. Positive discussions on students' strengths and weaknesses unveiled or amplified by distance learning generated closer relationships and greater collaboration among the significant adults in students' lives. In secondary schools, constructive, frequent, and constant exchanges are facilitated by effective and immediate communication. Parents continue to feel the presence of the teacher in the educational process of their children even at home:

From the questionnaire:

The constant relationship with the family has allowed for greater collaboration and, at the same time, made it possible to reassure the family on their children's learning and development, in this complex and uncertain moment. (Support teacher, lower secondary school)

During these turbulent and uncertain times, teachers felt they acquired a more accurate picture of families' true living conditions, a broader view of students' daily lives, a greater awareness of their school difficulties, and better comprehension of the educational dynamics involved:

As teachers, it was positive to have a better understanding of how children are managed at home, what the different roles of parents are respecting childcare, the economic and emotional conditions of families, their core values. (Class teacher, primary school)

With distance learning, families are more in contact with the challenges that we, as teachers, have to face every day...and also, they can better understand their children's academic difficulties. There is a greater exchange and greater openness towards teachers, which continues even now. (Support teacher, primary school)

If we consider the teacher-student relationship-the second element examined in the qualitative analysisthe negative impacts on students with disabilities during school closure are determined by the worsening of learning/teaching conditions, the role of home confinement on vertical and horizontal interactions, and the onset of new learning and teaching problems.

Especially in primary schools, the lack of many educational dimensions that were essential in the everyday school experience (i.e., physical and emotional contacts, face-to-face interactions, movements, different ways of communicating, etc.) makes distance learning particularly challenging, with serious effects on the quality of educational interactions. Contacts characterized by low levels of empathy and attunement, an excessive level of auditory and visual attention, and the paucity of non-verbal communication make interactions very difficult and perhaps even ineffective: All these negative aspects reduce opportunities to receive feedback, listen to students' needs and emotions, and encourage and support students. Teachers denounce a "very discouraging regression" in terms of learning loss and an increase in levels of insecurity among students with disabilities: The new learning conditions determined a drop in attention, concentration, and motivation in all students, but with a larger impact on students with disabilities:

What was lacking was the physical proximity that allows us to actually carry out the teaching and learning process, using various materials, be they structured or not, which can be manipulated and tested, while receiving immediate feedback, as well as the possibility of intervening, not just from behind a screen and not just in words. (Support teacher, primary school)

[During DAD] the three students with disabilities go in "stand-by": They turn off their brains and feel exempt from participating. During oral interrogations, they try to read maps, summaries, or notes (albeit badly): It seems they are not able to do any reasoning. It is a very discouraging regression. It is as if they are affected by lethargy: They gawk during the lesson, they do not follow the explanations and they do not concentrate at all. (Class teacher, primary school)

In secondary schools, teachers also report the negative experiences of "talking to the wall," that is, of ineffective communication and interaction with students. They also lose the possibility of constantly monitoring the progress in learning because they cannot control and revise homework and exercises in real-time.

Collecting feedback is harder during synch lessons than in other kinds of educational activities because teachers have to simultaneously manage two groups of students, online and in situ. New educational problems emerge in this scenario, exacerbated by a significant reduction in the support and interaction with peers, that limits the educational inclusion within the group of classmates. In terms of learning, furthermore, it becomes increasingly difficult to differentiate and customize activities for students with disabilities, mediating and simplifying live lessons in real-time for all students. This list of problems is even more complex for support teachers with poor digital competencies:

The difficulty of personalizing learning for students with disabilities is made apparent. Often, online lessons feel like one is "talking to the wall," without knowing if, on the other side, someone is listening to you or not. (Class teacher, upper secondary school)

Despite the negative perspectives underlined by these answers, a list of unexpected positive points also emerges from the written notes of the questionnaire. Positive experiences with students with disabilities are linked to the following aspects: a re-organization of the 
learning space, time, and patterns, in ways that are more suitable for students with disabilities; a more intense relationship between support teacher and students, balanced out by more independence on the students' part and fostered by a stronger cooperation between curricular and support teachers; new educational opportunities opened up by the massive use of ICT.

The situation deriving from school closure is characterized by positive aspects that improve the learning process of students with disabilities: Shorter lessons, with more time for homework and relaxation, as lessons are more carefully prepared and less improvised, are a better fit with the learning style of most students with disabilities, which in turn leads to less anxiety and stress linked to school performance. From a relational perspective, the teachers from our sample observe an intensification of their personal relationships with students in order to develop and monitor their PEI. They report experiencing supportive and positive connections with their students, fostering their independence and organizational skills:

The meetings on the Meet [platform], through the activation of a course dedicated to a small group of six disabled students, has improved upon the already well-established relationships in the classroom. It has favored a collective working-through of experiences and emotions and fostered exchanges regarding the proposed work activities. (Support teacher, primary school)

Some disabled students have acquired more independence, especially those who were already able to use the computer beforehand. (Class teacher, lower secondary school)

Some pupils participated more actively in synch online lessons than in face-to-face lessons. (Class teacher, primary school)
Last but not least, in respondents' opinions, school closure is also associated with new opportunities obtained from the use of ICTs, which proved positive and important compensatory tools for inclusive learning. For example, audiovisual tools and other inclusive communication channels between teacher and student promoted a gradual improvement in students' digital skills:

Students with learning difficulties, who had adopted compensatory tools before the pandemic, have benefited from the increased use of ICT. Not having to write manually for some came as a liberation. Furthermore, engaging with remote oral assessments has greatly reduced their anxiety. (Support teacher, upper secondary school)

The following analytical matrix (Table 3) summarizes the results of the qualitative analysis regarding teachers' opinions on their experience with students with disabilities during distance learning. Three negative trends and three positive trends are highlighted in the thematic analysis, corresponding to many indicators of these trends described earlier using teachers' answers (some examples are recalled and listed in the table).

A multifaceted picture of teachers' experiences with students with disabilities during the Covid-19 pandemic is provided. Among the negative trends, we can highlight the following: (a) a general worsening of teaching and learning conditions for students with disabilities; (b) a reduction in the quality of both vertical relationships (with teachers, especially curricular ones) and horizontal relationships (with classmates); and (c) the emergence of new teaching and learning problems stemming from the emergency scenario. Among the positive trends, we can identify, at one and at the same time, (a) an improvement of some learning conditions, which has served students with disabilities particularly well, (b) a renewed commitment among support teachers who

Table 3. Negative and positive trends emerging from teachers' opinions on their experience with students with disabilities during Covid-19 (analytical matrix).

\begin{tabular}{ll}
\hline Negative trends & Positive trends \\
\hline $\begin{array}{l}\text { 1. Worsening of teaching and learning conditions due to } \\
\text { lack of physical and emotional contact, lack of non-verbal } \\
\text { communication, excessive emphasis on listening, etc. }\end{array}$ & $\begin{array}{l}\text { 1. Improvement of learning conditions for students with } \\
\text { disabilities due to shorter lessons, more time for } \\
\text { homework and relaxation, an environment that can foster } \\
\text { concentration among students, etc. }\end{array}$ \\
\hline $\begin{array}{l}\text { 2. Worsening of the quality of educational relationships } \\
\text { due to a lack of time for curricular teachers to offer }\end{array}$ & $\begin{array}{l}\text { 2. Intensification of supportive relationships "at a } \\
\text { distance," i.e., supportive, continuous, and intense } \\
\text { personal encouragement to students in live lessons, } \\
\text { scarce interaction among classmates, little opportunities } \\
\text { for the practice of inclusion among students, etc. }\end{array}$ \\
\hline $\begin{array}{l}\text { 3. Emergence of new teaching and learning problems such } \\
\text { as the difficulty of teaching in a dual mode, difficulty in } \\
\text { differentiating and customizing activities and sync lessons, } \\
\text { increasing lack of concentration and motivation among } \\
\text { students, etc. }\end{array}$ & $\begin{array}{l}\text { 3. Development of new educational opportunities and } \\
\text { strategies such as the use of audiovisual tools and other } \\
\text { ICTs as compensatory tools (which empowered } \\
\text { opportunities for learning), the strengthening of individual } \\
\text { relationships to develop each student's PEl, etc. }\end{array}$ \\
\hline
\end{tabular}


developed very supportive relationships "at a distance," and (c) the emergence of new educational opportunities, mainly linked to the exploitation of the full potential of ICTs.

\section{Retrocession or Improvement in the Inclusion of Students With Disabilities? Conclusions and Recommendations}

Despite some methodological limitations, the survey helps us explore the "micro-decisions" that were taken by individual teachers during the challenging times of the first wave of Covid and can inspire reflections on how to improve the role of teachers during a permanent emergency (much like the one we are currently living at the time of writing, early 2022) and to better support school inclusion.

According to our findings, the Italian model of school inclusion was indeed challenged by the Covid-19 pandemic, but it brought about effects that were not as negative as one might have expected. In particular, the human resources on which inclusion is based (the combination of curricular teachers and support teachers), and on which it has been invested over the past decades, seem to have played an active role in ensuring the right to education to students with disabilities and basic school connection (i.e., maintaining a daily relationship with support teachers).

Many studies have already emphasized the complexity of situations and the variety of obstacles faced by students with disabilities during the Covid-19 pandemic. Our exploratory survey presented here confirms these problematic findings from the point of view of teachers in Italy. It recognizes that the pandemic has produced a general worsening of teaching and learning conditions, and highlights the difficulties faced by teachers, students, and parents-many of them related to the challenges of distance learning as such. Moreover, we can confirm that three negative impediments can diminish the inclusion of students with disabilities despite the efforts made by teachers to engage them in distance learning activities: the unavailability of adequate spaces and ICT devices at home; the lack of effective collaboration among parents; and a poor level of communication between teachers and families, which is fundamental in monitoring the home situation of students and-in cases of specific impairment and incapacity-to adapt the individual learning plan to the student's needs.

Our study, however, also allows us to highlight positive trends in the educational scenario marked by the pandemic. Italian teachers were able to take advantage of ICTs and the new relational conditions produced by distance learning in unexpected ways. They used them not only to foster the skills of students with disabilities, but also to enhance their independence and, unexpectedly, to listen to families more attentively. These improvements suggest that teachers have maintained their sensitivity towards students with disabilities during distance education, perhaps even increasing the intensity or finetuning the quality of their presence, with many daily contacts and improved inter-personal interaction.

In our view, the coexistence of negative and positive trends, of decline and improvement indicators, does not represent per se a cause for concern. This is because the main agents of school inclusion (teachers) could perceive the risk of losing any accrued advantage as a result of the progressist Italian legislation concerning school inclusion should they not be able to cope with such a dramatic and unexpected scenario. This is why they have mobilized every personal and professional resource available to prevent any decline in students' inclusion.

But the emerging positive trends, such as the acquisition of new skills and opportunities generated by the use of ICTs (for both teachers and students with disabilities), and the unforeseen improvement in empathy levels, at least among the most engaged teachers, lead us to conclude that it is time to trigger teachers' reflective thinking in order to save (and not waste) these rich learning experiences and teaching resources.

Serious investments on/for teaching and teachers must be made, both during the emergency period and beyond: from training methods on handling the needs of students with disabilities more effectively to making more channels for teacher-parent communication available; from digital skills training to awareness exercises on digital environments for distance learning, for students with disabilities in particular. These measures can help, with immediate and middle-term effects, improve complex school-family relationships, expand on the limited use of digital instruments by teachers (especially support teachers), and boost methodological innovation, all of which problems that have been underlined by previous research and confirmed also by our study.

\section{Conflict of Interests}

The authors declare no conflict of interests.

\section{References}

Agostinelli, F., Doepke, M., Sorrenti, G., \& Zilibotti, F. (2020). When the great equalizer shuts down: Schools, peers, and parents in pandemic times (Working Paper no. 28264). NBER.

Barnes, C. (2012). The social model of disability: Valuable or irrelevant? In N. Watson \& S. Vehmas (Eds.), The Routledge handbook of disability studies (pp. 12-29). Routledge.

Censis. (2020). La scuola e i suoi esclusi: Italia sotto sforzo. Diario della transizione 2020 [The school and its excluded students: Italy under pressure. A journal of the 2020 transition]. https://www.censis.it/ formazione/1-la-scuola-e-i-suoi-esclusi

D'Alessio, S. (2011). Inclusive education in Italy. Sense Publishers.

Dempsey, I. (2001). Principles and policies for inclusion. In 
P. Foreman (Ed.), Integration and inclusion in action (pp. 35-58). Harcourt Brace.

European Agency for Development in Special Needs Education. (2003). Special needs education in Europe. Eurydice.

Filosa, G., \& Parente, M. (2020). DAD e inclusion: Uno studio di caso durante l'emergenza sanitaria da Covid-19 [DAD and inclusion: A case study during the Covid-19 emergency]. SINAPPSI: Connessioni tra ricerca e politiche pubbliche, 10(3), 77-92.

Fondazione Agnelli. (2020). Oltre le distanze. L'indagine preliminare [Beyond the distance. A preliminary enquiry].

lanes, D., \& Bellacicco, R. (2020). Didattica a distanza durante il lockdown. L'impatto percepito dagli insegnanti sull'inclusione degli studenti con disabilità [Distance teaching during the lockdown. What teacher perceived about the impacts on students with disability]. L'integrazione scolastica e sociale, 19(3), 25-47. vIndire. (2020). Indagine tra i docenti italiani. Pratiche didattiche durante il lockdown [Enquiry among Italian teachers. Teaching practices during the lockdown]. http://www.indire.it/wp-content/ uploads/2020/07/Pratiche-didattiche-durante-illockdown-Report-2.pdf

Istat. (2020). L'inclusione scolastica degli alunni con disabilità [The school inclusion of students with disability].

Kuhfeld, M., Soland, J., Tarasawa, B., Johnson, A., Ruzek, E., \& Liu, J. (2020). Projecting the potential impacts of Covid-19 school closures on academic achievement. Educational Researcher, 49(8), 549-565.

MIUR. (2021). Focus: Principali dati della scuola. Avvio anno scolastico 2020/2021 [Focus: Main statistics on schooling. starting the school year 2020/2021].
Parmigiani, D., Benigno, V., Giusto, M., Silvaggio, C., \& Sperandio, S. (2020). E-inclusion: Online special education in Italy during the Covid-19 pandemic. Technology, Pedagogy and Education. Advance online publication. https://doi.org/10.1080/1475939X.2020. 1856714

Pavolini, E., Argentin, G., Falzetti, P., Galanti, M. T., Campodifiori, E., \& Le Rose, G. (2021). Tutti a casa: Il sistema di istruzione italiano alla prova del Covid-19 [Everyone at home: The Italian education system facing Covid-19]. Politiche Sociali/Social Policies, 2, 255-280.

Pellegrini, M., \& Maltinti, C. (2020). "School never stops": Measures and experience in Italian schools during the COVID-19 lockdown. Best Evid Chin Edu, 5(2), 649-663.

Petretto, D. R., Masala, I., \& Masala, C. (2020). School closure and children in the outbreak of Covid-19. Clinical Practice \& Epidemiology in Mental Health, 16, 189-191.

Schleicher, A. (2020). The impact of Covid-19 on education. Insights from education at a glance 2020. OECD.

UCSC. (2020). La situazione degli alunni con disabilità nell'era del Covid-19 secondo insegnanti ed educatori [The situation of students with disabilities in times of Covid-19 according to teachers and educators' opinion]. Department of Sociology, UCSC.

UNESCO. (2021). One year into Covid: Prioritizing education recovery to avoid a generational catastrophe. https://unesdoc.unesco.org/ark:/48223/pf 0000376984

UNICEF. (2021). Covid-19 and school closures. One year of education disruption.

United Nations. (2020). Education during Covid-19 and beyond (Policy Brief).

\section{About the Authors}

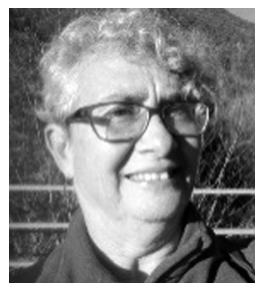

Maddalena Colombo is full professor of sociology of education, sociology of educational policy, and sociology of inequalities and differences at the Faculty of Education, Università Cattolica del Sacro Cuore (Italy). Since 2013 she is the director of the CIRMiB (Centre of Initiatives and Research on Migration) and the LaRIS (Laboratory of Social Research and Intervention), in Brescia. She is a member of the scientific board of several journals in Italy. She wrote more than 200 texts on the school system, socialization processes, and migration.

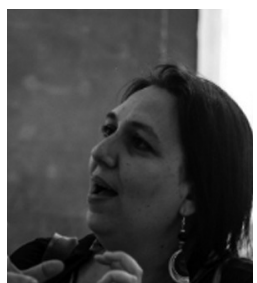

Mariagrazia Santagati is assistant professor of sociology of education at the Università Cattolica (Italy, Milan). Her main interests concern educational inequalities and the education-migration nexus, especially analyzed through qualitative research. Among her last publications are: "School Closure and Learning Experience in Italy: Giving Voice to Students, Families, and Teachers During the Covid-19 Pandemic" (2022), in Rassegna Italiana di Sociologia, and "Writing Educational Success: The Strategies of Immigrant-Origin Students in Italian Secondary Schools" (2021), in Social Sciences. 